\title{
Advances and obstacles in pressure-driven solid-state cooling: A review of barocaloric materials
}

\author{
Pol Lloveras and Josep-Lluís Tamarit \\ Grup de Caracterizació de Materials, Departament de Física, EEBE and Barcelona Research Center in Multiscale Science \\ and Engineering, Universitat Politècnica de Catalunya, Eduard Maristany, 10-14, 08019 Barcelona, Catalonia
}

Solid-state caloric effects promise since decades a disruptive cooling technology that should be more efficient and cleaner than current vapor compression. However, despite relevant achievements have been made, it is still difficult to foresee the time left for the development and wide implementation of competitive devices. Recent progress in the response of materials under hydrostatic pressure offers hope for overcoming some of the shortcomings posed by other solid-state methods and augurs a good outlook for barocaloric cooling, but there are still many struggles ahead to address in order to demonstrate its viability as a commercial cooling technique. Here we briefly review the milestones achieved in terms of barocaloric materials and discuss the pending challenges and expectations for the oncoming years.

Keywords: Calorimetry, phase transformation, thermal conductivity

\section{HIGHLIGHTS}

Barocaloric methods offer the widest range among solid-state caloric materials where to pick and choose. However, ideal barocaloric materials do not exist and a trade-off is required; Materials with high refrigerant capacity suffer from poor thermal conductivity and low density, and conversely.

\section{DISCUSSION}

Among reported barocaloric materials, recently identified plastic crystals appear best positioned for a real implementation.

There is an increasing need to realize the first barocaloric proof-of-concept for this method to earn credit as a feasible technology.

Since modern artificial cooling techniques based on vapor compression arose along the XIX century, nearly in parallel to the formulation of classical thermodynamics, it started the search for the ideal refrigerant. Fluids like ethyl ether, ammonia, methyl chloride, sulphur dioxide and carbon dioxide were used in early devices but they suffered from severe drawbacks, such as high flammability, toxicity, or low efficiency that limited a widespread use [1]. A milestone in this search took place during the first third of the XX century when halocarbons were identified as apparently optimal refrigerants, and dominated the market until nowadays. However, the continuous and abundant 
leakage of these gases into the atmosphere due to the lack of proper maintenance and waste management in billions of refrigerators, air conditioners and heat pumps worldwide [2] led halocarbons to be called into question because they posed a double environmental harm: On the one hand, the ozone-depleting potential of chlorofluorocarbons (CFCs) and hydrochlorofluorocarbons (HCFCs) [3] caused a hole in the ozone layer, discovered in 1985; On the other hand, the very high heat-trapping ability of HCFCs and hydrofluorocarbons (HFCs), most of which can reach a global warming potential (GWP) up to thousands of times that of $\mathrm{CO}_{2}$, have led these fluids to currently contribute up to $7.5 \%$ of global greenhouse emissions [4]. Moreover, cooling currently represents almost $20 \%$ of world-electricity consumption and its demand is expected to highly increase in the midterm mainly due to the rise of middle classes in emerging countries [4] so that the world-energy request in summer for cooling is expected to grow more than 30-fold from 2000 to 2100 and in the domestic sphere it will exceed that of heating by 2070 [5]. Consequently, halocarbons are since decades in the spotlight of policies against climate change. While CFCs were already prohibited all over the world upon 1996 following the Montreal Protocol, the production of HCFCs in USA [6] and the EU will be prohibited since this year 2020 and in 2030 all HCFCs will be completely forbidden as a result of the Kigali amendment to the Montreal protocol. Also, most important countries, including USA and China, are taking action in decreasing the use of HFCs, such as R-134a and R-410a, used in most automotive and household air conditioners, respectively, and, according to Regulation No 517/2014 [7], they shall be phased down in the EU to reach one fifth of 2014 market levels in 2030. Additionally, current cooling devices achieve moderate to high efficiencies, of about $20-60 \%$ of the Carnot cycle in many applications, which allows some room for improvement.

This situation makes evident why a significant amount of economic resources is being allocated towards an improvement of environmental sustainability of future cooling. This scientific and engineering challenge is addressed from different approaches. On the one hand, alternative fluids with low GWP are being proposed, such as ammonia, $\mathrm{CO}_{2}$, isobutane (R600) and related fluids, or hydrofluoroolefins, but meeting the standards of safety or efficiency is not trivial [8]. On the other hand, alternative techniques are investigated, being solid-state caloric effects considered amongst the most promising [9]. Interestingly, in addition to the avoidance of harmful fluids, these methods would offer higher efficiencies, resulting in a lower global environmental impact [10], and might lead to new cooling applications due to unique properties that are absent in vapor compression, such as downscalability.

Thermodynamically, caloric effects are defined following the fundamental Carnot cycle as isothermal entropy changes $\Delta S$ and adiabatic temperature changes $\Delta T$ that undergoes a material when it is subjected to changes in an external field. Actually, solid-state caloric effects exploit the same fundamental principle as vapor compression: To exchange a large amount of heat, caloric effects are usually sought near first-order phase transitions (FOPT) so that the transition is driven forth and back cyclically by suitable external fields such as magnetic, electric or mechanic, giving rise to magnetocaloric (MC), electrocaloric (EC), elastocaloric (uniaxial stress-driven, $\mathrm{eC}$ ) and barocaloric (hydrostatic pressure-driven, BC) effects, respectively. Then, following the exothermic transition the caloric material releases the latent heat to the environment, and following the endothermic transition the caloric material absorbs it from the target to be cooled. Therefore, the exchange of the latent heat is controlled by means of external work done by the external field, which is appropriately applied and removed during the cycle.

First reported experimental evidences of eC, MC and EC effects date back to 1805 [11], 1917 [12] and 1930 [13], respectively, but it was not until few decades ago [14] when they have raised renewed interest as alternative cooling method in widespread applications. $\mathrm{MC}, \mathrm{EC}$ and eC effects have also 
proven their technical viability with the completion of each proof-of-concepts. Each kind of caloric effect exhibits specific advantages, conferring them interest for particular application segments. MC devices have already demonstrated high efficiencies, and are noiseless [4]. EC effects are large in thin films and are therefore promising for microscale cooling of electronic devices, where overheating, which causes almost $50 \%$ of the failures [15], hinders the development of more compact chips. Also, their flexibility could lead to integrated cooling in wearables [16]. eC effects show very large temperature changes and good efficiencies, and offers opportunities in automotive applications [17].

Given the early stage [18-20] of research and development of BC materials and methods, it is difficult to establish a clear mid-term future for this field. Notwithstanding, a few clues can be identified. The possibility of using material in form of powder circumvents the mechanical or electrical breakdown suffered by many materials when subjected to relatively large external fields along millions of cycles as required in devices. Solutions such as multilayer thin film capacitors for EC still need improvements to increase the breakdown fields [21], and the fabrication processes make it difficult large scale applications. MC composites made of epoxy- or polymer-bounded magnetic particles [22] compromise the heat transfer and thermal mass of the composites [23]. On the other hand, the range of suitable giant BC compounds surpasses that of MC and EC materials: Best MC materials are based on rare-earth elements or gadolinium, which are inappropriate for large scale commercialization due to geopolitical reasons [4], whereas best EC materials contain lead [24], whose toxicity is stimulating research in finding lead-free alternatives [25]. As for eC effects, theoretically the range of eC materials is the largest among caloric effects because any lattice deformation may be sensitive to a uniaxial stress, but in practice most materials undergo strong fatigue and fracture under repetitive tensile loading across a FOPT. Consequently, although compressive loading promises fatigueresistant operation [26], most promising eC materials are actually restricted to shape memory alloys and polymers [27]. Instead, giant BC effects have been reported in a very extensive and diverse range of materials, as it has been summarized in Table I, along with their thermodynamic and BC properties. While we cannot ensure the list to be comprehensive, we can state that it gathers the vast majority of materials studied experimentally so far. Notice that more than half of the listed materials have been published upon 2018, which indicates the youth and current rapid growth of this field.

Nevertheless, despite the theoretically large number of potential candidates, finding really good materials is an arduous task, as it was well described in Ref. [28]. On the one hand, both $\Delta S$ and $\Delta T$ are sought to be large, because $T \Delta S$ is the heat exchanged isothermally at a temperature $T$ and $\Delta T$ needs to be large to enable thermal equilibrium with the cold end at a desired temperature below the thermal bath. Usually, at FOPTs, $\Delta S$ is mostly contributed by the transition entropy change $\Delta S_{t}$ whereas $\Delta T$ is inverse to the heat capacity $C_{p}$, and mostly related to the pressure sensitivity of the transition temperature $d T / d p$, which according to the Clausius-Clapeyron equation $d T / d p=$ $\Delta V_{t} / \Delta S_{t}$ (where $\Delta V_{t}$ is the volume change at the transition). Therefore, good indicators of giant $\mathrm{BC}$ materials are large latent heat, $\Delta H_{t}=T \Delta S_{t}$, and large $\Delta V_{t}$ to compensate the large $\Delta S_{t}$ and thus obtain large $d T / d p$ that will result in a larger $\Delta T$ at low pressures. Also, transition temperatures should of course lie close to the operational temperature range required for a given application. On the other hand, thermal hysteresis (and also large transition widths mostly related to athermal behavior in alloys [29]) in FOPTs may prevent the system from recovering the initial state after completing a cycle. Overcoming this obstacle introduces a minimum pressure threshold required to obtain reversible BC effects, $p_{\text {rev }}$, which leads to an excess input work and, hence, a subsequent decrease of performance. Therefore, transitions with small hysteresis (and small transition widths) are highly preferable. In addition to $\Delta S$ and $\Delta T$, another parameter to assess and compare the suitability of caloric materials is the Refrigerant Capacity (RC) or Relative Cooling Power (RCP) [30]. These two quantities account for the area below the peak that is usually displayed by $\Delta S$ vs. $T$ associated with FOPTs, and are ambiguously defined in literature as $\int \Delta S d T$ or $\Delta S_{\max } \times$ [Full Width at Half Maximum], where the Full Width at Half Maximum is the peak width in temperature at half of the peak maximum. In any case, both RC and RCP refer to the amount of heat that can be transferred between cold and hot 
reservoirs in a cycle. However, these quantities do not take into account the input work needed to drive the cycle and therefore a complementary useful parameter is the Coefficient of Refrigeration Performance (CRP), which can be approximately calculated for BC effects as $\mathrm{CRP} \approx\left(\Delta S \times \Delta T_{\text {rev }}\right) /$ $\left(p \Delta V_{t} / 2\right)[31]\left(\Delta T_{r e v}\right.$ refers to the reversible adiabatic temperature changes).

Last but not least, additional features that caloric materials should fulfill to be suitable for competitive applications, also include high thermal conductivity, large density, nontoxicity and economic and geopolitical availability of the raw materials. As if that was not enough, some of the aforementioned desired features are detrimental to others, and therefore finding a compromise is the only possible way. A significant example concerns dynamic disorder in crystals. As a source of entropy, materials undergoing order-disorder transitions have been attracted particular interest because the increase in the number of accessible configurations from $N_{2}$ to $N_{1}$ occurring across the transition contributes to a specific entropy change $R M^{-1} \log \left(N_{1} / N_{2}\right)$, that in some cases may reach very large values. Unfortunately, dynamic disorder usually goes against thermal conductivity [32] and density, so it seems hard to foresee an ideal material gathering all the aforementioned properties at the same time. Therefore, a trade-off between opposing features must be reached. In this respect, solutions for heat transfer enhancement in low thermal conducting materials have been proposed, and mainly consist of increasing the contact area by means of, for instance, adding highly conductive nanostructures, such as nanoparticles, nanolayers or vapor grown carbon fibers [33], or introducing the material into highly conductive nanoporous matrices [24,34]. While these strategies have yielded good results, they are detrimental for the energy density of the resulting composites.

BC effects near FOPTs for solid-state cooling were boosted a decade ago with a MC material undergoing a magnetostructural transformation [20], where the non- isochoric character of the transition hinted at the possibility of driving caloric effects using pressure. Since then, a number of metallic alloys including Heusler alloys [35-38], manganites [39-42] and others [43,44] have been studied, across either ferromagnetic or metamagnetic transitions involving a diversity of magnetic behavior such as, for instance, noncollinear magnetism resulting from geometrical frustration caused by antiferromagnetic interactions [39,41]. While many of them show small BC effects, in the last years $\Delta S$ of $\sim 60 \mathrm{~J} \mathrm{~K}^{-1} \mathrm{~kg}^{-1}$ and $\Delta T \sim 10 \mathrm{~K}$ under few kbar have been reported. Despite these materials usually show modest values for $\Delta T$ and relatively high hysteresis, they are also appealing because they enjoy a relatively high density [27] and thermal conductivity $\left(\mathrm{Gd}_{2} \mathrm{Si}_{5} \mathrm{Ge}_{5}: \kappa=5.64 \mathrm{~W} \mathrm{~m}^{-1} \mathrm{~K}^{-1}[45]\right.$; La-Fe-Co-Si: $\kappa=7 \mathrm{~W} \mathrm{~m}^{-1} \mathrm{~K}^{-1}$ [45]; $\mathrm{Ni}_{2} \mathrm{MnGa}: \kappa \sim 16 \mathrm{~W} \mathrm{~m}^{-1} \mathrm{~K}^{-1}$ [46]; Ni-Mn-In: $\kappa \sim 5-13 \mathrm{~W} \mathrm{~m}^{-1}$ $\mathrm{K}^{-1}$ [47]; MnCoGe/MnNiGe: $\kappa \sim 5-6 / 7-10 \mathrm{~W} \mathrm{~m}^{-1} \mathrm{~K}^{-1}$ [48], $\mathrm{Fe}_{49} \mathrm{Rh}_{51}: \kappa=7.1 \mathrm{~W} \mathrm{~m}^{-1} \mathrm{~K}^{-1}$; $\mathrm{Ni}_{0.85} \mathrm{Fe}_{0.15} \mathrm{~S}: \kappa=11.5 \mathrm{~W} \mathrm{~m}^{-1} \mathrm{~K}^{-1}$ [45]). However, best metallic barocaloric materials in terms of $\Delta S$ and $\Delta T$ are Mn-based alloys, and this element exhibits the lowest thermal conductivity amongst all metals and almost two orders of magnitude lower than typical values. Another advantage lies in their multiferroic character which makes them suitable for multicaloric applications [49,50], where magnetic and mechanical fields are applied simultaneously or sequentially. Also, variations in composition, via doping or alloying with other elements, offer opportunities to tune their physical properties such as operational temperatures or improved phase transition properties $[35,36,45]$.

Chemical flexibility is particularly outstanding in metalorganic complexes, where the almost unlimited combinations open routes to an extremely large number of compounds and, so, to find systems with specific properties. These compounds are gaining prominence in many areas of materials science and recently have been also proposed as promising $\mathrm{BC}$ agents. There, the cage-bridge structure consisting of a central metallic atom surrounded by organic or inorganic ligands, allows huge volume changes at phase transitions which, accompanied by giant but not colossal transition entropy changes, yields extremely high sensitivity of the transition to pressure (as mandated by the Clausius-Clapeyron 
equation). In particular, typical $d T / d p$ values lie in the range $100-200 \mathrm{~K} \mathrm{GPa}^{-1}$ (despite values of up to $\sim 400 \mathrm{~K} \mathrm{GPa}^{-1}$ have been reached [51]) that may lead to large $\Delta T$ at very low pressure changes, which may result in very good cooling performance. Examples include hybrid organic-inorganic perovskites (HOIPs) [51-55] and spin-crossover (SCO) transitions [56-59]. In HOIPs, giant transition entropy changes emerge basically due to positional and rotational disorder. For instance, in [TPrA] $\left[\mathrm{Mn}(\mathrm{dca})_{3}\right]$ [51] (TPrA=tetrapropylammonium cation, $\left(\mathrm{CH}_{3} \mathrm{CH}_{2} \mathrm{CH}_{2}\right)_{4} \mathrm{~N}^{+}$, dca=dicyanamide anion, $\left.\left[\mathrm{N}(\mathrm{CN})_{2}\right]^{-}\right)$, the disordering in the $\mathrm{C}$ atoms of the TPrA-pending propyl groups and in the $\mathrm{N}$ and $\mathrm{C}$ atoms of the dca ligands that arise at the transition yields $N_{1} / N_{2} \sim 10.3$, which results in a transition entropy change $\Delta S_{t} \sim 42.5 \mathrm{~J} \mathrm{~K}^{-1} \mathrm{~kg}^{-1}$. An extensive list of HOIPs has also been provided as potential good BC candidates [55]. In the SCO complex $\left[\mathrm{CrI}(\text { depe })_{2}\right.$ ] [58], the transition entropy change is mostly contributed by phonons, whereas the large change in the local magnetic moment $\Delta S_{\mathrm{mag}}=k_{\mathrm{B}} \ln \left[\left(2 S_{\mathrm{HS}}+\right.\right.$ $\left.1) /\left(2 S_{\mathrm{LS}}+1\right)\right]$ is secondary. A shortcoming for these compounds is the very low thermal conductivity [60] due to the porous structure, $\mathrm{H}$ bridges and disorder. Actually, single crystals can reach moderate $\left(\kappa \sim 0.1-0.4 \mathrm{~W} \mathrm{~m}^{-1} \mathrm{~K}^{-1}[61,62]\right)$ or even notable values $\left(\kappa \sim 1.3 \mathrm{~W} \mathrm{~m}^{-1} \mathrm{~K}^{-1}\right.$ [63]). However, the use of single crystals in $\mathrm{BC}$ cooling applications is difficult to foresee because large single crystals of metal complexes are difficult to grow and powderization is expected upon cyclic pressurizationdepressurization, and powder exhibits much smaller thermal conductivity $\left(\kappa<0.1 \mathrm{~W} \mathrm{~m}^{-1} \mathrm{~K}^{-1}\right)$ $[62,64]$.

Ferroelectric materials are also potential BC candidates due to large volume changes and disorder of ions associated with the ferroelectric transition. For instance, the release of occupational and rotational disorder of the three ions in ferrielectric ammonium sulphate yields $N_{1} / N_{2}=8$, consistent with an entropy increase of $\sim 130 \mathrm{~J} \mathrm{~K}^{-1} \mathrm{~kg}^{-1}$. Half of this entropy change occur across an abrupt FOPT that enables giant $\mathrm{BC}$ effects of $\Delta S \sim 60 \mathrm{~J} \mathrm{~K}^{-1} \mathrm{~kg}^{-1}$ at low pressures of $0.1 \mathrm{GPa}$ [65]. In $\mathrm{PbTiO}_{3}$, the experimental value for the transition entropy change is too large to account for a displacive phase transition and thus reveals the order-disorder character of the transition [66], which is associated with 6 possible positions in $<001>$ directions for $\mathrm{Pb}$ atoms in the paraelectric phase. Nonetheless, the value is still too small to indicate a full ordering of the $\mathrm{Pb}$ positions so that in the ferroelectric tetragonal phase $\mathrm{Pb}$ atoms should still exhibit some disorder. Ferroelectric materials usually show values for the thermal conductivity that, while lower than metallic alloys, $\left(\left(\mathrm{NH}_{4}\right)_{2} \mathrm{SO}_{4}: \kappa \sim 0.8 \mathrm{~W} \mathrm{~m}^{-1} \mathrm{~K}^{-1}\right.$ [67]; $\mathrm{BaTiO}_{3}: \kappa \sim 0.6 \mathrm{~W} \mathrm{~m}^{-1} \mathrm{~K}^{-1}$; $\mathrm{PbTiO}_{3}: \kappa \sim 510 \mathrm{~W} \mathrm{~m}^{-1} \mathrm{~K}^{-1}$ [68]) are larger than in metal complexes.

Similarly to ammonium sulphate, giant BC effects reported in ferroelastic fluorides have been associated with the positional disorder in the atomic cations and/or orientational order-disorder of ammonium tetrahedra cations, and of the anionic octahedra counterparts [69-71]. To the best knowledge of the authors, no values for thermal conductivity are known for these compounds.

In the superionic conductor AgI, the abrupt increase in the ionic conductivity occurring across the endothermic transition is caused because a significant volume contraction of the lattice enables a strong positional disorder of $\mathrm{Ag}^{+}$ions, that can hop among 12 different sites. Therefore, in this case $N_{1} / N_{2}=$ 12 is obtained, rendering $R M^{-1} \log \left(N_{1} / N_{2}\right) \sim 88 \mathrm{~J} \mathrm{~K}^{-1} \mathrm{~kg}^{-1}$. In this case, the volume contraction most likely contributes negatively to the transition entropy change, which is consistent with transition entropy changes of $\Delta S_{\mathrm{t}} \sim 70 \mathrm{~J} \mathrm{~K}^{-1} \mathrm{~kg}^{-1}$ [72]. Regarding the thermal conductivity for AgI, $\kappa \sim 0.2 \mathrm{~W}$ $\mathrm{m}^{-1} \mathrm{~K}^{-1}$ in the ordered phase close to the phase transition, which decreases down to 0.15 because the ionic mobility does not carry heat but interrupts the phonon propagation [73], cutting off the phonon mean free path. Large BC effects have also been predicted in the superionic phases of $\mathrm{Li}_{3} \mathrm{~N}$ [74] and $\mathrm{Cu}_{2} \mathrm{Se}$ [75] away from the phase transition, where the application of pressure causes large changes in the superionic conductivity. 
Graphene [76] and polymers have also shown giant BC effects in the absence of phase transitions. In the latter case, large entropy changes originate from the rearrangement of chains. Polymers are also affected by low densities and low thermal conductivity (e.g. $\kappa \sim 0.13 \mathrm{~W} \mathrm{~m}^{-1} \mathrm{~K}^{-1}$ for vulcanized natural rubber [77]).

Finally, a breakthrough has recently been made with the detection of colossal $\mathrm{BC}$ effects in plastic crystals [78-81], that can reach several hundreds of $\mathrm{J} \mathrm{K}^{-1} \mathrm{~kg}^{-1}$, wich are comparable to those shown by the HFC R-134a. These values originate in the fact that the orientational order of the constituents is lost across a first-order phase transition, typically yielding an enormous latent heat. In the case of neopentylglycol $\left[\left(\mathrm{CH}_{3}\right)_{2} \mathrm{C}\left(\mathrm{CH}_{2} \mathrm{OH}\right)_{2}\right]$, for instance, a large number of possible molecular orientations in the plastic phase renders $N_{1} / N_{2}=60$, being the main cause for BC effects of about $450 \mathrm{~J} \mathrm{~K}^{-1} \mathrm{~kg}^{-1}$ at $p \sim 0.3 \mathrm{GPa}$ [79]. Similar BC effects have been reported in $\mathrm{PG}\left[\left(\mathrm{CH}_{3}\right) \mathrm{C}\left(\mathrm{CH}_{2} \mathrm{OH}\right)_{3}\right]$, also emerging mainly from the 110 different molecular configurations allowed in the plastic phase [80]. The limitations for the applicability of these compounds are the low density, relatively large hysteresis and low thermal conductivities caused by the strong disorder in plastic crystals (for NPG, $\kappa \sim 0.11$ $0.37 \mathrm{~W} \mathrm{~m}^{-1} \mathrm{~K}^{-1}$ [82-85], for PG $\left.\kappa \sim 0.23-0.36 \mathrm{~W} \mathrm{~m}^{-1} \mathrm{~K}^{-1}[82,86]\right)$. In these materials, improvements of thermal conductivity and reduction of hysteresis have been investigated for thermal energy storage applications, such as embedding of NPG in porous graphite matrices, or introducing graphene nanoplatelets in PG [87].

As an overiew, Table II provides an orientative averaged assessment of some BC features for some material families, which reflects that no ideal BC compounds exist. Probably, as it occurs with halocarbon fluids used in current cooling devices, different choices for future BC technologies will be made depending on the specific application and apparatus.

It is thus clear that this last decade has experienced continuous new findings and record breakings in BC materials. Now, while there is still room to thrive in this field, materials research should be supported by engineers to develop a proof-of-concept that hopefully transfers this promise to real technology. First steps have been done to address this major challenge [108,109] so that we look forward to seeing relevant advances in the near future. Moreover, applied research in barocaloric technology will give a realistic insight on several aspects of performance that are now only suppositions. For instance, what pressures are realizable in terms of safety and cost. For its characteristics, BC cooling methods offers all kind of applications including household and large-scale commercial refrigeration and air conditioning and electronics. Moreover, looking at other caloric effects $[4,110]$, technology based on BC effects could be conceived for other energy-related applications. For instance, for energy harvesting and power generation, waste heat from other hot sources could be used to drive an endothermic phase transition at constant volume, leading to a pressure increase that could be converted into mechanical energy at will by means of a piston. Also, high-temperature barocaloric materials could find applications for heat pumping in industry.

As far as we can see, although important steps still have to be accomplished towards applicability to earn credit as a real clean and cost-effective alternative, in the light of recent progress and ongoing research, barocaloric methods hold great promise in the midterm.

\section{ACKNOWLEDGMENTS}


This work was supported by the MINECO project FIS2017-82625-P from the spanish government and the DGU project 2017SGR-42 from the catalan government. 
TABLE I. Barocaloric properties in giant barocaloric materials. Transition temperatures $T$, and dependence of $T$ on pressure, $d T / d p$, correspond to heating data for pure compounds whereas they have been averaged over heating and cooling data for martensitic alloys. Data for BC effects $\Delta S$ and $\Delta T$ in brackets are irreversible data. Pressure $p$ refers to the value for which $\Delta S, \Delta T, \mathrm{CRP}$ and RC were obtained.

\begin{tabular}{|c|c|c|c|c|c|c|c|c|c|c|c|}
\hline Material & $\begin{array}{l}\boldsymbol{T} \\
\mathrm{K}\end{array}$ & $\begin{array}{l}\boldsymbol{d T} / \boldsymbol{d p} \\
\mathrm{K} \mathrm{GPa}^{-1}\end{array}$ & $\begin{array}{l}\Delta \boldsymbol{V}_{\boldsymbol{t}} \\
10^{-6} \mathrm{~m}^{3} \mathrm{~kg}^{-1}\end{array}$ & hyst. & $\begin{array}{l}\Delta \boldsymbol{T} \\
\mathrm{K}\end{array}$ & $\begin{array}{l}\Delta \boldsymbol{S} \\
\mathrm{J} \mathrm{K}^{-1} \mathrm{~kg}^{-1}\end{array}$ & $\begin{array}{l}\Delta \boldsymbol{S} \\
\mathrm{J} \mathrm{K}^{-1} \mathrm{~cm}^{-3}\end{array}$ & CRP & $\begin{array}{l}\text { RC } \\
\mathrm{kJ} \mathrm{kg}^{-1}\end{array}$ & $\begin{array}{l}\boldsymbol{p} \\
\mathrm{GPa}\end{array}$ & Ref. \\
\hline \multicolumn{12}{|c|}{ Magnetostructural } \\
\hline $\mathrm{Gd}_{2} \mathrm{Si}_{5} \mathrm{Ge}_{5}$ & 260 & 35 & 1.33 & 5 & $(1.1)$ & 6.2 & 0.047 & - & 0.025 & 0.20 & [88] \\
\hline $\mathrm{LaFe}_{11.33} \mathrm{Co}_{0.47} \mathrm{Si}_{1.2}$ & 250 & -94 & 1.39 & - & $(2.2)$ & 8.7 & 0.062 & - & $(0.18)$ & 0.20 & [89] \\
\hline $\mathrm{Ni}_{49.26} \mathrm{Mn}_{36.08} \mathrm{In}_{14.66}$ & 293 & 18 & 0.61 & 10 & $(4.5)$ & 10 & 0.082 & - & $(0.12)$ & 0.25 & [20] \\
\hline $\mathrm{Ni}_{2.02} \mathrm{Mn}_{1.36} \mathrm{In}_{0.62}$ & 346 & 18.3 & 0.61 & 4 & (4) & 10 & 0.082 & - & 0.046 & 0.25 & [35] \\
\hline $\mathrm{Ni}_{2.05} \mathrm{Mn}_{1.30} \mathrm{In}_{0.65}$ & 330 & 16.5 & 0.61 & 6 & (4) & 5 & 0.041 & - & 0.015 & 0.25 & [35] \\
\hline $\mathrm{Ni}_{1.99} \mathrm{Mn}_{1.37} \mathrm{In}_{0.64}$ & 329 & 19.5 & 0.61 & 4 & (4) & 6 & 0.049 & - & 0.026 & 0.25 & [35] \\
\hline $\mathrm{Ni}_{1.99} \mathrm{Mn}_{1.34} \mathrm{In}_{0.67}$ & 306 & 13.7 & 0.61 & 3 & (2) & 4 & 0.033 & - & 0.009 & 0.20 & [35] \\
\hline $\mathrm{Ni}_{2.00} \mathrm{Mn}_{1.32} \mathrm{In}_{0.68}$ & 275 & 18.8 & 0.61 & 5 & (3) & 4 & 0.033 & - & 0.018 & 0.25 & [35] \\
\hline $\begin{array}{l}\mathrm{Ni}_{43.3} \mathrm{Co}_{7.4} \mathrm{Mn}_{30.8} \mathrm{Ga}_{18.5} \\
{\left[\mathrm{Ni}_{42.7} \mathrm{Co}_{8.87} \mathrm{Mn}_{31.67}\right.}\end{array}$ & 5403 & 2.6 & 0.4 & 15 & - & (12) & $(0.096)$ & - & $(0.13)$ & 0.25 & [90] \\
\hline $\left.\mathrm{Ga}_{14.98} \mathrm{In}_{2.01}\right]$ & 417 & 2.7 & 0.6 & 13 & - & (17) & $(0.136)$ & - & $(0.20)$ & 0.25 & [90] \\
\hline \multicolumn{12}{|c|}{$\left[\mathrm{Ni}_{42.2} \mathrm{Co}_{8.4} \mathrm{Mn}_{32.3}\right.$} \\
\hline $\left.\mathrm{Ga}_{15} \mathrm{In}_{2.1}\right]$ & 485 & 2.7 & 0.6 & 13 & - & $(17)$ & $(0.136)$ & - & $(0.195)$ & 0.25 & [90] \\
\hline $\mathrm{Ni}_{58.3} \mathrm{Mn}_{17.1} \mathrm{Ga}_{24.6}$ & 318 & 4 & 0.064 & 11 & $(2.8)$ & (13.6) & - & - & $(0.056)$ & 1.05 & [91] \\
\hline $\mathrm{Ni}_{50} \mathrm{Mn}_{31.5} \mathrm{Ti}_{18.5}$ & 249 & 2.6 & 1.9 & 12 & 3.7 & 35 & 0.246 & $\sim 0.8$ & 0.294 & 0.38 & [37] \\
\hline $\mathrm{Ni}_{35.5} \mathrm{Co}_{14.5} \mathrm{Mn}_{35} \mathrm{Ti}_{15}$ & 291 & 50 & 2.3 & 7 & 2.3 & 8.5 & 0.059 & 0.48 & 0.022 & 0.1 & [92] \\
\hline $\mathrm{Ni}_{44.6} \mathrm{Co}_{5.5} \mathrm{Mn}_{35.5} \operatorname{In}_{14.4}$ & 272 & 44 & 0.70 & 19 & (6) & $(15.6)$ & $(0.126)$ & - & 0.247 & 0.6 & [93] \\
\hline $\mathrm{Ni}_{42.3} \mathrm{Co}_{7.9} \mathrm{Mn}_{38.8} \mathrm{Sn}_{11.0}$ & 0327 & 47 & 1.32 & 17 & 5 & 15 & 0.121 & 0.28 & 0.398 & 0.62 & [94] \\
\hline $\mathrm{Fe}_{49} \mathrm{Rh}_{51}$ & 310 & 60 & 1.0 & 10 & 5 & 12 & 0.12 & 0.50 & $(0.2)$ & 0.25 & {$[43,44]$} \\
\hline $\mathrm{MnCoGe}_{0.99} \mathrm{In}_{0.01}$ & 310 & -77 & -4.91 & 8 & $(9.4)$ & $(52)$ & $(0.41)$ & - & (1.4) & 0.30 & [40] \\
\hline $\mathrm{MnCoGeB}_{0.03}$ & 286 & -100 & -5.0 & 10 & 12.5 & 30 & 0.25 & 0.7 & 0.48 & 0.26 & [42] \\
\hline $\mathrm{Mn}_{3} \mathrm{GaN}$ & 290 & -65 & -1.43 & - & $(4.8)$ & $(21.6)$ & $(0.15)$ & - & $(0.125)$ & 0.093 & [39] \\
\hline $\mathrm{Mn}_{3} \mathrm{NiN}$ & 262 & -14 & 0.58 & 8 & (3.5) & $(35)$ & $(0.24)$ & - & $(0.15)$ & 0.28 & [41] \\
\hline $\mathrm{MnNiSi}_{0.62} \mathrm{FeCoGe}_{0.38}$ & 8338 & -75 & $\sim 3.5$ & 10 & (16) & 57 & 0.42 & - & $(1.5)$ & 0.27 & [95] \\
\hline $\mathrm{MnNiSi}_{0.61} \mathrm{FeCoGe}_{0.39}$ & 9311 & -70 & 3.6 & 4 & 6 & 44 & 0.31 & 0.67 & 0.39 & 0.26 & [36] \\
\hline $\mathrm{MnNiSi}_{0.60} \mathrm{FeCoGe}_{0.40}$ & 0280 & -73 & 3.9 & 12 & 4 & 47 & 0.33 & 0.48 & 0.17 & 0.23 & [36] \\
\hline $\mathrm{MnNiSi}_{0.59} \mathrm{FeCoGe}_{0.41}$ & 1247 & -75 & 3.7 & 14 & 1.8 & 24 & 0.17 & 0.17 & 0.17 & 0.23 & [36] \\
\hline $\mathrm{Co}_{50} \mathrm{Fe}_{2.5} \mathrm{~V}_{31.5} \mathrm{Ga}_{16}$ & 277 & 25 & 0.85 & 10 & 6 & 31 & - & 0.93 & 0.32 & 0.5 & [38] \\
\hline $\mathrm{Ni}_{0.95} \mathrm{Fe}_{0.05} \mathrm{~S}$ & 274 & -75 & 2.95 & 12.1 & $(9.2)$ & $(39.6)$ & $(0.214)$ & - & $(0.387)$ & 0.1 & [45] \\
\hline $\mathrm{Ni}_{0.875} \mathrm{Fe}_{0.125} \mathrm{~S}$ & 294 & -75 & 3.36 & 14.0 & $(9.2)$ & $(49.5)$ & $(0.267)$ & - & $(0.483)$ & 0.1 & [45] \\
\hline $\mathrm{Ni}_{0.85} \mathrm{Fe}_{0.15} \mathrm{~S}$ & 303 & -75 & 3.19 & 11.5 & $(8.3)$ & $(52.8)$ & $(0.285)$ & - & $(0.448)$ & 0.1 & [45] \\
\hline $\mathrm{Ni}_{0.825} \mathrm{Fe}_{0.175} \mathrm{~S}$ & 318 & -75 & 3.24 & 19.6 & (10.7) & $(46.8)$ & $(0.253)$ & - & $(0.527)$ & 0.1 & [45] \\
\hline
\end{tabular}

Ferroelastic fluorides and oxyfluorides

\begin{tabular}{|c|c|c|c|c|c|c|c|c|c|c|c|}
\hline $\mathrm{Rb}_{2} \mathrm{KTiOF}_{5}$ & 215 & 110 & 4.69 & - & $(16.5)$ & (46) & $(0.118)$ & - & $(2.602)$ & 0.5 & [69] \\
\hline$\left(\mathrm{NH}_{4}\right)_{2} \mathrm{NbOF}_{5}$ & 220,260 & 45 & $2.07,4.83$ & - & $(16)$ & (100) & $(0.145)$ & - & (7.054) & 1.0 & [69] \\
\hline$\left(\mathrm{NH}_{4}\right)_{2} \mathrm{MoO}_{2} \mathrm{~F}_{4}$ & 270 & 93 & 0.78 & - & (12) & (50) & $(0.144)$ & - & $(3.55)$ & 0.5 & [70] \\
\hline$\left(\mathrm{NH}_{4}\right)_{2} \mathrm{WO}_{2} \mathrm{~F}_{4}$ & 201 & 13 & 1.12 & - & (12.6) & $(50.3)$ & $(0.180)$ & - & $(2.147)$ & 0.9 & [70] \\
\hline$\left(\mathrm{NH}_{4}\right)_{2} \mathrm{SnF}_{6}$ & 110 & -157 & 3.48 & 0.5 & (11) & $(61)$ & $(0.175)$ & - & $(0.95)$ & 0.10 & [71] \\
\hline $\mathrm{K}_{2} \mathrm{TaF}_{7}$ & 486.2 & 220 & -9.23 & 37 & (20) & (36) & $(0.140)$ & - & $(1.46)$ & 0.20 & [96] \\
\hline
\end{tabular}

Ferroelectrics

\begin{tabular}{|c|c|c|c|c|c|c|c|c|c|c|c|}
\hline $\mathrm{PbTiO}_{3}$ & 763 & -140 & 0.46 & 15 & $(-1.9)$ & (2.7) & $(0.024)$ & - & $(0.043)$ & 0.026 & [66] \\
\hline$\left(\mathrm{NH}_{4}\right)_{2} \mathrm{SO}_{4}$ & 220 & -51 & 2.9 & 4 & 9.4 & 58 & 0.1 & 1.49 & 0.63 & 0.25 & [65] \\
\hline $\mathrm{BaTiO}_{3}$ & 400 & -56 & 0.19 & 4 & 4 & 1.47 & 0.0088 & 0.67 & 0.012 & 0.10 & [97] \\
\hline $\mathrm{NH}_{4} \mathrm{HSO}_{4}$ & 160 & -123 & 8.04 & - & $(-10)$ & (60) & (0.106) & - & $(0.750)$ & 0.10 & [98] \\
\hline
\end{tabular}

Superionic conductors

\begin{tabular}{|c|c|c|c|c|c|c|c|c|c|c|c|}
\hline AgI & 420 & -135 & 7.4 & 25 & 18 & 60 & 0.33 & 1.17 & 1.1 & 0.25 & [72] \\
\hline $\mathrm{Li}_{3} \mathrm{~N}^{*}$ & 300 & - & - & $\sim 0$ & $\sim 2.8$ & 32 & 0.041 & - & - & 1 & [74] \\
\hline
\end{tabular}




\begin{tabular}{|c|c|c|c|c|c|c|c|c|c|c|c|}
\hline \multirow[t]{2}{*}{$\mathrm{Cu}_{2} \mathrm{Se}^{*}$} & \multirow[t]{2}{*}{$400-700$} & \multirow[t]{2}{*}{-} & \multirow[t]{2}{*}{-} & $\sim 0$ & $\sim 10$ & $\sim 15-45$ & \multicolumn{2}{|c|}{$\sim 0.11-0.32$} & \multirow[t]{2}{*}{-} & \multirow[t]{2}{*}{1} & \multirow[t]{2}{*}{ [75] } \\
\hline & & & & \multicolumn{5}{|c|}{ Hybrid organic-inorganic perovskites } & & & \\
\hline$[\mathrm{TPrA}] \mathrm{Mn}[\mathrm{dca}]_{3}$ & 330 & 231 & 10 & 0.9 & 4.1 & 30.5 & 0.046 & 3.51 & 0.054 & 0.007 & [51] \\
\hline$[\mathrm{TPrA}] \mathrm{Cd}[\mathrm{dca}]_{3}$ & 385 & 382 & 5.3 & 3 & 1.4 & 11.5 & 0.0087 & 0.87 & 0.015 & 0.007 & {$[52]$} \\
\hline$\left(\mathrm{CH}_{3}\right)_{2} \mathrm{NH}_{2} \mathrm{Mg}(\mathrm{HCOC}$ & O) $3 \quad 263$ & -43 & 2.28 & $0-2$ & $(8.1)$ & $(39.9)$ & $(0.063)$ & - & $(0.335)$ & 0.206 & [53] \\
\hline$\left[\left(\mathrm{CH}_{3}\right)_{4} \mathrm{~N}\right] \mathrm{Mn}\left[\mathrm{N}_{3}\right]_{3}$ & 305 & 120 & 9.4 & $\sim 7$ & - & 70 & 0.11 & - & 0.28 & 0.09 & [54] \\
\hline \multicolumn{12}{|c|}{ Spin Crossovers } \\
\hline$\left[\mathrm{Fe}(\mathrm{pzt})_{6}\right](\mathrm{PF} 6)_{2}$ & 74 & 290 & 16.44 & $\sim 0$ & (27) & (46) & $(\sim 0.070)$ & - & $(1.380)$ & 0.1 & [99] \\
\hline$\left[\mathrm{Fe}(\text { hyptrz) })_{3}\right] \mathrm{A}_{2} \cdot \mathrm{H}_{2} \mathrm{O}$ & 273 & 332 & - & $\sim 0$ & (10) & $(56)$ & - & - & $(1.223)$ & 0.09 & {$[100]$} \\
\hline$\left[\mathrm{Fe}(\text { phen })_{2}(\mathrm{NCS})_{2}\right]$ & 170 & $170-440$ & 33 & 0.3 & (11) & (78) & $(0.129)$ & - & $(2.950)$ & 0.1 & {$[101,102]$} \\
\hline$\left[\mathrm{FeL}_{2}\right]\left[\mathrm{BF}_{4}\right]_{2}$ & 260 & $100-200$ & 15.33 & 4 & 6 & - & - & - & - & 0.10 & [57] \\
\hline$\left[\mathrm{CrI}_{2}\right]\left[(\mathrm{depe})_{2}\right]$ & 168.5 & 520 & 28.6 & - & $(10.6)$ & $(40)$ & - & - & $(0.3583)$ & 0.20 & [58] \\
\hline \multicolumn{12}{|c|}{ Polymers } \\
\hline PVDF-TrFE-CTFE & 368 & - & - & - & 18.6 & $(120)$ & $(0.22)$ & - & - & 0.2 & [103] \\
\hline VNR rubber & 300 & - & - & - & 11 & - & - & - & - & 0.173 & [104] \\
\hline PDMS rubber & 283 & - & - & - & 28 & $(150)$ & $(0.155)$ & - & - & 0.39 & [105] \\
\hline \multicolumn{12}{|l|}{ [Nitrile Butadiene } \\
\hline Rubber] & 314 & - & - & - & 16.4 & 59 & 0.082 & - & 2.7 & 0.39 & [106] \\
\hline \multicolumn{12}{|l|}{ [Acetoxy Silicone } \\
\hline Rubber] & 250 & 270 & - & 14 & 21 & 182 & 0.175 & - & 13.3 & 0.173 & [107] \\
\hline \multicolumn{12}{|c|}{ Plastic crystals } \\
\hline$\left(\mathrm{CH}_{3}\right)_{2} \mathrm{C}\left(\mathrm{CH}_{2} \mathrm{OH}\right)_{2}$ & 315 & 103 & 46 & $\sim 24$ & 7.5 & 421 & 0.448 & 0.60 & 2.8 & 0.25 & [79] \\
\hline$\left(\mathrm{CH}_{3}\right) \mathrm{C}\left(\mathrm{CH}_{2} \mathrm{OH}\right)_{3}$ & 354 & 86 & 38 & $\sim 12$ & 10 & 490 & 0.602 & 1.07 & 4.9 & 0.24 & [80] \\
\hline$\left(\mathrm{CH}_{3}\right)_{3} \mathrm{C}\left(\mathrm{CH}_{2} \mathrm{OH}\right)$ & 232 & 170 & 45.5 & $\sim 40$ & 16 & 293 & 0.238 & 0.87 & 2.0 & 0.26 & [80] \\
\hline$\left(\mathrm{NH}_{2}\right) \mathrm{C}\left(\mathrm{CH}_{2} \mathrm{OH}\right)_{3}$ & 406.8 & 26 & 41.9 & $\sim 80$ & (8) & $(600)$ & $(0.792)$ & - & $(5.5)$ & 0.25 & [80] \\
\hline$\left(\mathrm{NH}_{2}\right)\left(\mathrm{CH}_{3}\right) \mathrm{C}\left(\mathrm{CH}_{2} \mathrm{OH}\right.$ & H) 2352.7 & 75 & 48.1 & $\sim 55$ & (15) & $(690)$ & $(0.837)$ & - & $(10.9)$ & 0.25 & {$[80]$} \\
\hline $\mathrm{C}_{60}$ & 257 & 170 & 4.6 & 3 & 9.7 & 30 & 0.051 & 1.35 & 0.50 & 0.10 & [81] \\
\hline
\end{tabular}


TABLE II. Barocaloric performance of different features on average for some families of materials. $*=$ Poor. $* *=$

Fair. $* * *=$ Good. $* * * *=$ Excellent.

\begin{tabular}{|c|c|c|c|c|c|c|c|}
\hline Material family & $\Delta S$ & $\Delta T$ & Reversibility & Pressure & Thermal conductivity & Density & Cost \& availability \\
\hline Magnetostructural & $* *$ & $*$ & $* *$ & $*$ & $* * * *$ & $* * * *$ & $* *$ \\
Ferroelastic fluorides and oxyfluorides & $* *$ & $* *$ & $* * *$ & $* * *$ & $* *$ & $* *$ & $* * *$ \\
Ferroelectrics & $* *$ & $* *$ & $* * * *$ & $* * *$ & $* *$ & $* *$ & $* * *$ \\
Superionic conductor & $* *$ & $* *$ & $* *$ & $* *$ & $* *$ & $* *$ & $* *$ \\
Hybrid organic-inorganic perovskites & $* *$ & $* * *$ & $* * * *$ & $* * * *$ & $* *$ & $* *$ \\
Spin Crossovers & $* * *$ & $* * *$ & $* * * *$ & $* * * *$ & $*$ & $* *$ & $* *$ \\
Polymers & $* * *$ & $* * *$ & $* * *$ & $*$ & $* *$ & $* *$ & $* *$ \\
Plastic crystals & $* * * *$ & $* * * *$ & $* *$ & $* *$ & $* *$ & $* *$ & $* *$ \\
\hline
\end{tabular}

\section{REFERENCES}

[1] S. F. Pearson, Refrigerants past, present and future, international Congress of Refrigeration (Washington DC, USA), 2003. Available at http://www.r744.com/ files/pdf_597.pdf (accessed September 2020).

[2] T. Peters: A cool world - Defining the energy conundrum of cooling for all (2018). Available at https://www.birmingham.ac.uk/Documents/college-eps/energy/Publications/2018-clean-cold report.pdf, (accessed November 2019).

[3] S. Solomon, Stratospheric ozone depletion: A review of concepts and history, Rev. Geophys. 37, 275, (1999).

[4] A. Kitanovski, Energy Applications of Magnetocaloric Materials, Adv. Energy Mater. 10, 1903741 (2020).

[5] R. Gauß, G. Homm, and O. Gutfleisch, The Resource Basis of Magnetic Refrigeration, J. Ind. Ecol. 21, 1291 (2017).

[6] EPA: Phaseout of Ozone-Depleting Substances (ODS). Available at https://www.epa.gov/odsphaseout, (accessed September 2020).

[7] Regulation (EU) No 517/2014 of the European Parliament and of the Council of 16 April 2014 on fluorinated greenhouse gases and repealing Regulation (EC) No 842/2006 (2014): Available at https://eur-lex.europa.eu/legal-content/EN/ALL/?uri=uriserv:OJ.L .2014.150.01.0195.01.ENG (accessed July 2020).

[8] 2018 Assessment Report of the Refrigeration, Air Conditioning and HeatPumps Technical Options Committee, https://ozone.unep.org/sites/default/files/ 2019-04/RTOC-assessment-report-2018_0.pdf, (accessed September 2020).

[9] Energy savings potential and rd\&d opportunities for non-vapor-compression hvac technologies, https://www.energy.gov/sites/prod/files/2014/03/f12/ Non-

Vapor\%20Compression\%20HVAC\%20Report.pdf, (accessed July 2019).

[10] C. Aprea, A. Greco, A. Maiorino, and C. Masselli, The environmental impact of solid-state materials working in an active caloric refrigerator compared to a vapor compression cooler, Int. J. Heat Technol. 36, 1155 (2018).

[11] J. Gough, A description of a property of caoutchouc, or indian rubber, Mem. Lit. Phil. Soc. Manchester 1, 288 (1805).

[12] P. Weiss and A. Piccard, Le phénomène magnétocalorique, J. Phys. (Paris) 7, 103 (1917). 
[13] P. Kobeko and J. Kurtschatov, Dielektrische Eigenshaften der Seignettesalzkristalle, Zeit. Phys. 66, $192(1930)$.

[14] V. K. Pecharsky and K. A. Gschneidner, Giant magnetocaloric effect in $\mathrm{Gd}_{5}\left(\mathrm{Si}_{2} \mathrm{Ge}_{2}\right)$, Phys. Rev. Lett. 78, 4494 (1997).

[15] G. Krishan, K. C. Aw, and R. N. Sharma, Synthetic jet impingement heat transfer enhancement -A review, Applied Thermal Engineering 149, 1305 (2019).

[16] J. Shi, D. Han, Z. Li, L. Yang, S.-G. Lu, Z. Zhong, J. Chen, Q. Zhang, and X. Qian, Electrocaloric Cooling Materials and Devices for Zero-Global-Warming-Potential, High-Efficiency Refrigeration, Joule 3, 1200 (2019).

[17] K. Engelbrecht, Future prospects for elastocaloric devices, J. Phys.: Energy 1, 021001 (2019).

[18] E. L. Rodríguez and F. E. Filisko, Thermoelastic temperature changes in poly(methyl methacrylate) at high hydrostatic pressure: Experimental, J. Appl. Phys. 53, 6536 (1982).

[19] K. A. Müller, F. Fauth, S. Fischer, M. Koch, A. Furrer, and P. Lacorre, Cooling by adiabatic pressure application in $\mathrm{Pr}_{1-x} \mathrm{La}_{x} \mathrm{NiO}_{3}$, Appl. Phys. Lett. 73, 1056 (1998).

[20] L. Mañosa, D. González-Alonso, A. Planes, E. Bonnot, M. Barrio, J.-L. Tamarit, S. Aksoy, and M. Acet, Giant solid-state barocaloric effect in the Ni-Mn-In magnetic shape-memory alloy, Nat. Mater. 9, 478 (2010).

[21] X. Moya, E. Defay, N. D. Mathur, and S. Hirose, Electrocaloric effects in multilayer capacitors for cooling applications, MRS Bulletin 43, 291-294 (2018).

[22] F. Zhu, J. Lin, W. Jiang, C. Yang, L. Li, X. Zhang, W. Song, X. Zhu, P. Tong, and Y. Sun, Enhanced mechanical properties and large magnetocaloric effect in epoxy-bonded $M n_{0.98} C o G e$, Scripta Materialia 150, 96 (2018).

[23] C. Aprea, A. Greco, A. Maiorino, and C. Masselli, Enhancing the Heat Transfer in an Active Barocaloric Cooling System Using Ethylene-Glycol Based Nanofluids as Secondary Medium, Energies 12, 10.3390/en12152902 (2019).

[24] M. Valant, Electrocaloric materials for future solid-state refrigeration technologies, Prog. Mater. Sci. 57, 980 (2012).

[25] A. Kumar, A. Thakre, D.-Y. Jeong, and J. Ryu, Prospects and challenges of the electrocaloric phenomenon in ferroelectric ceramics, J. Mater. Chem. C 7, 6836 (2019).

[26] L. Porenta, P. Kabirifar, A. Žerovnik, M. Čebron, B. Žužek, M. Dolenec, M. Brojan, JakaTušek, Thin-walled Ni-Ti tubes under compression: ideal candidates for efficient and fatigue-resistant elastocaloric cooling, Applied Mater. Today 20, 100712, 2020)

[27] L. Mañosa and A. Planes, Materials with Giant Mechanocaloric Effects: Cooling by Strength, Adv. Mater. 29, 1603607 (2017).

[28] T. Gottschall, K. P. Skokov, M. Fries, A. Taubel, I. Radulov, F. Scheibel, D. Benke, S. Riegg, and O. Gutfleisch, Making a Cool Choice: The Materials Library of Magnetic Refrigeration, Adv. Energy Mater. 9, 1901322 (2019).

[29] F. J. Pérez-Reche, E. Vives, L. Mañosa, and A. Planes, Athermal Character of Structural Phase Transitions, Phys. Rev. Lett. 87, 195701 (2001).

[30] K. A. Gschneidner and V. K. Pecharsky, Magnetocaloric Materials, Annu. Rev. Mater. Sci. 30, 387 (2000).

[31] E. Brück, H. Yibole, and L. Zhang, A universal metric for ferroic energy materials, Philos. Trans. A 
Math. Phys. Eng. Sci. 374, 20150303 (2016).

[32] A. Krivchikov, G. Vdovichenko, O. Korolyuk, F. Bermejo, L. Pardo, J. Tamarit, A. Jezowski, and D. Szewczyk, Effects of site-occupation disorder on the low-temperature thermal conductivity of molecular crystals, J. Non-Cryst. Solids 407, 141 (2015), 7th IDMRCS: Relaxation in Complex Systems.

[33] E.-B. S. Mettawee and G. M. Assassa, Thermal conductivity enhancement in a latent heat storage system, Sol. Energy 81, 839 (2007).

[34] X. Wang, Q. Guo, Y. Zhong, X. Wei, and L. Liu, Heat transfer enhancement of neopentyl glycol using compressed expanded natural graphite for thermal energy storage, Renew. Energy 51, 241 (2013).

[35] E. Stern-Taulats, A. Planes, P. Lloveras, M. Barrio, J.-L. Tamarit, S. Pramanick, S. Majumdar, S. Yüce, B. Emre, C. Frontera, and L. Mañosa, Tailoring barocaloric and magnetocaloric properties in lowhysteresis magnetic shape memory alloys, Acta Mater. 96, 324 (2015).

[36] P. Lloveras, T. Samanta, M. Barrio, I. Dubenko, N. Ali, J.-L. Tamarit, and S. Stadler, Giant reversible barocaloric response of $(\mathrm{MnNiSi})_{1-x}(\mathrm{FeCoGe})_{x}(x=0.39,0.40,0.41)$, APL Mater. 7, 061106 (2019)

[37] A. Aznar, A. Gràcia-Condal, A. Planes, P. Lloveras, M. Barrio, J.-L. Tamarit, W. Xiong, D. Cong, C. Popescu, and L. Mañosa, Giant barocaloric effect in all-\$d\$-metal Heusler shape memory alloys, Phys. Rev. Mater. 3, 044406 (2019).

[38] H. Liu, Z. Li, Y. Zhang, Z. Ni, K. Xu, and Y. Liu, A large barocaloric effect associated with paramagnetic martensitic transformation in $\mathrm{Co}_{50} \mathrm{Fe}_{2.5} \mathrm{~V}_{31.5} \mathrm{Ga} a_{16}$ quaternary Heusler alloy, Scr. Mater. 177, 1 (2020).

[39] D. Matsunami, A. Fujita, K. Takenaka, and M. Kano, Giant barocaloric effect enhanced by the frustration of the antiferromagnetic phase in $M n_{3} G a N$, Nat. Mater. 14, 73 (2014).

[40] R. R. Wu, L. F. Bao, F. X. Hu, Q. Z. Huang, J. Wang, X. L. Dong, G. N. Li, J. R. Sun, F. R. Shen, T. Y. Zhao, X. Q. Zheng, L. C. Wang, Y. Liu, W. L. Zuo, Y. Y. Zhao, M. Zhang, Z. C. Wang, C. Q. Jin, G. H. Ro, X. F. Han, and B. G. Shen, Giant barocaloric effect in hexagonal Ni $i_{2}$-type Mn-Co-Ge-In compounds around room temperature, Sci. Rep. 5, 18027 (2015).

[41] D. Boldrin, E. Mendive-Tapia, J. Zemen, J. B. Staunton, T. Hansen, A. Aznar, J.-L. Tamarit, M. Barrio, P. Lloveras, J. Kim, X. Moya, and L. F. Cohen, Multisite Exchange-Enhanced Barocaloric Response in $\mathrm{Mn}_{3} \mathrm{NiN}$, Phys. Rev. X 8, 041035 (2018).

[42] A. Aznar, P. Lloveras, J.-Y. Kim, E. Stern-Taulats, M. Barrio, J. L. Tamarit, C. F. Sánchez-Valdés, J. L. Sánchez Llamazares, N. D. Mathur, and X. Moya, Giant and Reversible Inverse Barocaloric Effects near Room Temperature in Ferromagnetic MnCoGeB 0.03 , Adv. Mater. 31, 1903577 (2019).

[43] E. Stern-Taulats, A. Planes, P. Lloveras, M. Barrio, J.-L. Tamarit, S. Pramanick, S. Majumdar, C. Frontera, and L. Mañosa, Barocaloric and magnetocaloric effects in Fe ${ }_{49} R h_{51}$, Phys. Rev. B 89, 214105 (2014).

[44] E. Stern-Taulats, A. Gracia-Condal, A. Planes, P. Lloveras, M. Barrio, J.-L. Tamarit, S. Pramanick, S. Majumdar, and L. Mañosa, Reversible adiabatic temperature changes at the magnetocaloric and barocaloric effects in $\mathrm{Fe}_{49} \mathrm{Rh}_{51}$, Appl. Phys. Lett. 107, 152409 (2015).

[45] J. Lin, P. Tong, X. Zhang, Z. Wang, Z. Zhang, B. Li, G. Zhong, J. Chen, Y. Wu, H. Lu, L. He, B. Bai, L. Ling, W. Song, Z. Zhang, and Y. Sun, Giant room-temperature barocaloric effect at the electronic phase transition in $N i_{1-x} F e_{x} S$, Mater. Horiz. 7, 2690 (2020).

[46] Y. K. Kuo, K. M. Sivakumar, H. C. Chen, J. H. Su, and C. S. Lue, Anomalous thermal properties of the Heusler alloy $\mathrm{Ni}_{2+} \mathrm{Mn}_{1-x} \mathrm{Ga}$ near the martensitic transition, Phys. Rev. B 72, 054116 (2005). 
[47] B. Zhang, X. X. Zhang, S. Y. Yu, J. L. Chen, Z. X. Cao, and G. H. Wu, Giant magnetothermal conductivity in the NiMnIn ferromagnetic shape memory alloys, Appl. Phys. Lett. 91, 012510 (2007).

[48] Q. Zheng, S. E. Murray, Z. Diao, A. Bhutani, D. P. Shoemaker, and D. Cahill, Thermal transport through the magnetic martensitic transition in $M n_{x} M G e(M=C o, N i)$, Phys. Rev. Mater. 2, 075401 (2018).

[49] E. Stern-Taulats, T. Castán, L. Mañosa, A. Planes, N. D. Mathur, and X. Moya, Multicaloric Materials and effects, MRS Bull. 43, 295 (2018).

[50] T. Gottschall, A. Gràcia-Condal, M. Fries, A. Taubel, L. Pfeuffer, L. Mañosa, A. Planes, K. P. Skokov, and O. Gutfleisch, A multicaloric cooling cycle that exploits thermal hysteresis, Nat. Mater. 17, 929 (2018).

[51] J. M. Bermúdez-García, M. Sánchez-Andújar, S. Castro-García, J. López-Beceiro, R. Artiaga, and M. A. Senanís-Rodríguez, Giant barocaloric effect in the ferroic organic-inorganic hybrid [TPrA] [Mn(dca)3] perovskite under easily accessible pressures, Nat. Commun. 8, 15715 (2017).

[52] J. M. Bermúdez-García, S. Yáñez-Vilar, A. García-Fernández, M. Sánchez-Andújar, S. CastroGarcía, J. López-Beceiro, R. Artiaga, M. Dilshad, X. Moya, and M. A. Señańs-Rodríguez, Giant barocaloric tunability in $\left[\left(\mathrm{CH}_{3} \mathrm{CH}_{2} \mathrm{CH}_{2}\right)_{4} \mathrm{~N}\right] \mathrm{Cd}\left[\mathrm{N}(\mathrm{CN})_{2}\right]_{3}$ hybrid perovskite, J. Mater. Chem. C 6, 9867 (2018).

[53] M. Szafrański, W.-J. Wei, Z.-M. Wang, W. Li, and A. Katrusiak, Research Update: Tricritical point and large caloric effect in a hybrid organic-inorganic perovskite, APL Mater. 6, 100701 (2018).

[54] J. Salgado-Beceiro, A. Nonato, R. X. Silva, A. García-Fernández, M. Sánchez-Andújar, S. CastroGarcía, E. Stern-Taulats, M. A. Señarís-Rodríguez, X. Moya, and J. M. Bermúdez-García, Near-roomtemperature reversible giant barocaloric effects in $\left[\left(\mathrm{CH}_{3}\right)_{4} \mathrm{~N}\right] \mathrm{Mn}\left[\mathrm{N}_{3}\right]_{3}$ hybrid perovskite, Mater. Adv. (2020) DOI: 10.1039/d0ma00652a

[55] J. M. Bermúdez-García, M. Sánchez-Andújar, M. A. Señarís-Rodríguez, A New Playground for Organic-Inorganic Hybrids: Barocaloric Materials for Pressure-Induced Solid-State Cooling, J. Phys. Chem. Lett. 8, 4419 (2017).

[56] K. G. Sandeman, Research Update: The mechanocaloric potential of spin crossover compounds, APL Mater. 4, 111102 (2016).

[57] S. P. Vallone, A. N. Tantillo, A. M. dos Santos, J. J.Mo- laison, R. Kulmaczewski, A. Chapoy, P. Ahmadi, M. A. Halcrow, and K. G. Sandeman, Giant Barocaloric Effect at the Spin Crossover Transition of a Molecular Crystal, Adv. Mater. 31, 1807334 (2019).

[58] P. J. von Ranke, B. P. Alho, P. H. S. da Silva, R. M. Ribas, E. P. Nobrega, V. S. R. de Sousa, M. V. Colaço, L. F. Marques, M. S. Reis, F. M. Scaldini, L. B. L. Escobar, and P. O. Ribeiro, Large barocaloric effect in spin-crossover complex [CrI (depe) $\left._{2}\right]$, J. Appl. Phys. 127, 165104 (2020).

[59] M. S. Reis, Magnetocaloric and barocaloric effects of metal complexes for solid state cooling: Review, trends and perspectives, Coord. Chem. Rev. 417, 213357 (2020).

[60] K. Ridier, Y. Zhang, M. Piedrahita-Bello, C. M. Quintero, L. Salmon, G. Molnár, C. Bergaud, and A. Bousseksou, Heat Capacity and Thermal Damping Properties of Spin-Crossover Molecules: A New Look at an Old Topic, Adv. Mater. 32, 2000987 (2020).

[61] B. Huang, A. McGaughey, and M. Kaviany, Thermal conductivity of metal-organic framework 5 (MOF-5): Part I. Molecular dynamics simulations, Int. J. Heat Mass Transfer 50, 393 (2007).

[62] J. Huang, X. Xia, X. Hu, S. Li, and K. Liu, A general method for measuring the thermal conductivity of MOF crystals, Int. J. Heat Mass Transfer 138, 11 (2019).

[63] W. D. C. B. Gunatilleke, K. Wei, Z. Niu, L. Wojtas, G. Nolas, and S. Ma, Thermal conductivity 
of a perovskite-type metal-organic framework crystal, Dalton Trans. 46, 13342 (2017).

[64] N. Nik Ibrahim, S. M. Said, A. Mainal, M. Mohd Sabri, N. Abdullah, M. Megat Hasnan, H. Che Hassan, M. Mohd Salleh, and W. Wan Mohd Mahiyiddin, Molecular design strategies for spin-crossover (\{SCO\}) metal complexes (Fe(II) and Co(II)) for thermoelectricity, Mater. Res. Bull. 126, 110828 (2020).

[65] P. Lloveras, E. Stern-Taulats, M. Barrio, J.-L. Tamarit, S. Crossley, W. Li, V. Pomjakushin, A. Planes, L. Mañosa, N. D. Mathur, and X. Moya, Giant barocaloric effects at low pressure in ferrielectric ammonium sulphate, Nat. Commun. 6, 8801 (2015).

[66] E. A. Mikhaleva, I. N. Flerov, M. V. Gorev, M. S. Molokeev, A. V. Cherepakhin, A. V. Kartashev, N. V. Mikhashenok, and K. A. Sablina, Caloric characteristics of $\{P\} b\{T\} i\{O\} \$ 3 \$$ in the temperature range of the ferroelectric phase transition, Phys. Solid State 54, 1832 (2012).

[67] T. K. Song, S.-M. Lee, Y. S. Yu, and S.-I. Kwun, Dielectric and thermal studies on the high temperature phases of $\left(\mathrm{NH}_{4}\right)_{2} \mathrm{SO}_{4}$, Ferroelectrics 159, 215 (1994).

[68] Y. Fu and D. J. Singh, Thermal conductivity of perovskite $\mathrm{KTaO}_{3}$ and $\mathrm{PbTiO}_{3}$ from first principles, Phys. Rev. Mater. 2, 094408 (2018).

[69] M. V. Gorev, E. V. Bogdanov, I. N. Flerov, V. N. Voronov, and N. M. Laptash, Barocaloric Effect in Oxyfluorides $\mathrm{Rb}_{2} \mathrm{KTiOF}_{5}$ and $\left(\mathrm{NH}_{4}\right)_{2} \mathrm{NbOF}_{5}$, Ferroelectrics 397, 76 (2010).

[70] M. V. Gorev, E. V. Bogdanov, I. N. Flerov, A. G. Kocharova, and N. M. Laptash, Investigation of thermal expansion, phase diagrams, and barocaloric effect in the $\left(\mathrm{NH}_{4}\right)_{2} \mathrm{WO}_{2} \mathrm{~F}_{4}$ and $\left(\mathrm{NH}_{4}\right)_{2} \mathrm{MoO}_{2} \mathrm{~F}_{4}$ oxyfluorides, Phys. Solid State 52, 167 (2010).

[71] I. N. Flerov, A. V. Kartashev, M. V. Gorev, E. V. Bogdanov, S. V. Mel'nikova, M. S. Molokeev, E. I. Pogorelt- sev, and N. M. Laptash, Thermal, structural, optical, dielectric and barocaloric properties at ferroelastic phase transition in trigonal $\left(\mathrm{NH}_{4}\right)_{2} \mathrm{SnF} \mathrm{F}_{6}$ : A new look at the old compound, J. Fluor. Chem. 183, 1 (2016).

[72] A. Aznar, P. Lloveras, M. Romanini, M. Barrio, J.-L. Tamarit, C. Cazorla, D. Errandonea, N. D. Mathur, A. Planes, X. Moya, and L. Mañosa, Giant barocaloric effects over a wide temperature range in superionic conductor AgI, Nat. Commun. 8, 1851 (2017).

[73] M. Goetz and J. Cowen, The thermal conductivity of silver iodide, Solid State Commun. 41, 293 (1982).

[74] A. K. Sagotra, D. Chu, and C. Cazorla, Room-temperature mechanocaloric effects in lithium-based superionic materials, Nat. Commun. 9, 3337 (2018).

[75] J. Min, A. K. Sagotra, and C. Cazorla, Large barocaloric effects in thermoelectric superionic materials, Phys. Rev. Mater. 4, 015403 (2020).

[76] N. Ma and M. S. Reis, Barocaloric effect on graphene, Sci. Rep. 7, 13257 (2017).

[77] C. Aprea, A. Greco, A. Maiorino, and C. Masselli, The environmental impact of solid-state materials working in an active caloric refrigerator compared to a vapor compression cooler, Int. J. Heat Technol. 36, 801 (2018).

[78] B. Li, Y. Kawakita, S. Ohira-Kawamura, T. Suga- hara, H. Wang, J. Wang, Y. Chen, S. I. Kawaguchi, S. Kawaguchi, K. Ohara, K. Li, D. Yu, R. Mole, T. Hattori, T. Kikuchi, S.-I. Yano, Z. Zhang, Z. Zhang, W. Ren, S. Lin, O. Sakata, K. Nakajima, and Z. Zhang, Colossal barocaloric effects in plastic crystals, Nature 567, 506 (2019).

[79] P. Lloveras, A. Aznar, M. Barrio, P. Negrier, C. Popescu, A. Planes, L. Mañosa, E. SternTaulats, A. Avramenko, N. D. Mathur, X. Moya, and J.-L. Tamarit, Colossal barocaloric effects near room temperature in plastic crystals of neopentylglycol, Nat. Commun. 10, 1803 (2019). 
[80] A. Aznar, P. Lloveras, M. Barrio, P. Negrier, A. Planes, L. Mañosa, N. D. Mathur, X. Moya, and J.L. Tamarit, Reversible and irreversible colossal barocaloric effects in plastic crystals, J. Mater. Chem. A 8, 639 (2020).

[81] J. Li, D. Dunstan, X. Lou, A. Planes, L. Mañosa, M. Barrio, J. L. Tamarit, and P. Lloveras, Reversible barocaloric effects over a large temperature span in fullerite $C_{60}$, J. Mater. Chem. A 8, 20354 (2020)

[82] C. H. Son and J. H. Morehouse, Thermal conductivity enhancement of solid-solid phase-change materials for thermal storage, J. Thermophys. Heat Transfer 5, 122 (1991).

[83] S. Akbulut, Y. Ocak, K. Keslioglu, and N. Marasli, Thermal conductivities of solid and liquid phases for neopentylglycol, aminomethylpropanediol and their binary alloy, J. Phys. Chem. Sol. 70, 72 (2009).

[84] B. Praveen and S. Suresh, Experimental study on heat transfer performance of neopentyl glycol/CuO composite solid-solid PCM in TES based heat sink, Eng. Sci. Technol. Int. J. 21, 1086 (2018).

[85] Z.-Y. Zhang, Y.-P. Xu, and M.-L. Yang, Measurement of the Thermal Conductivities of Neopentylglycol, 1,1,1-Trihydroxymethylpropane, and Their Mixture in the Temperature Range from $20^{\circ} \mathrm{C}$ to Their Supermelting Temperatures, J. Chem. Eng. Data 45, 1060 (2000).

[86] N. Zhang, Y. Song, Y. Du, G. Xiao, and Y. Gui, A Novel Solid-Solid Phase Change Material: Pentaglycerine/Expanded Graphite Composite PCMs, Adv. Eng. Mater. 20, 1800237 (2018).

[87] N. Zhang, Y. Jing, Y. Song, Y. Du, and Y. Yuan, Thermal properties and crystallization kinetics of pentaglycerine/graphene nanoplatelets composite phase change material for thermal energy storage, Int. J. Energy Res. 44, 448 (2020).

[88] S. Yuce, M. Barrio, B. Emre, E. Stern-Taulats, A. Planes, J.-L. Tamarit, Y. Mudryk, K. A. Gschneidner, V. K. Pecharsky, and L. Mañosa, Barocaloric effect in the magnetocaloric prototype $\mathrm{Gd}_{5} \mathrm{Si}_{2} \mathrm{Ge}_{2}$, Appl. Phys. Lett. 101, 071906 (2012).

[89] L. Mañosa, D. Gonzalez-Alonso, A. Planes, M. Barrio, J. L. Tamarit, I. S. Titov, M. Acet, A. Bhattacharyya, and S. Majumdar, Inverse barocaloric effect in the giant magnetocaloric La-Fe-Si-Co compound, Nat. Commun. 2, 595 (2011).

[90] L. Mañosa, E. Stern-Taulats, A. Planes, P. Lloveras, M. Barrio, J.-L. Tamarit, B. Emre, S. Yüce, S. Fabbrici, and F. Albertini, Barocaloric effect in metamagnetic shape memory alloys, Phys. Stat. Sol. (b) 251, 2114 (2014).

[91] X. J. He, K. Xu, S. X. Wei, Y. L. Zhang, Z. Li, and C. Jing, Barocaloric effect associated with magneto-structural transformation studied by an effectively indirect method for the $N i_{58.3} M n_{17.1} G a_{24.6}$ Heusler alloy, J. Mater. Sci. 52, 2915 (2017).

[92] Z. Wei, Y. Shen, Z. Zhang, J. Guo, B. Li, E. Liu, Z. Zhang, and J. Liu, Low-pressure-induced giant barocaloric effect in an all-d-metal Heusler $\mathrm{Ni}_{35.5} \mathrm{Co}_{14.5} \mathrm{Mn}_{35} \mathrm{Ti}_{15}$ magnetic shape memory alloy, APL Mater. 8, 051101 (2020).

[93] X. He, S. Wei, Y. Kang, Y. Zhang, Y. Cao, K. Xu, Z. Li, and C. Jing, Enhanced barocaloric effect produced by hydrostatic pressure-induced martensitic transformation for $\mathrm{Ni}_{44.6} \mathrm{Co}_{5.5} \mathrm{Mn}_{35.5} \mathrm{In}_{14.4} \mathrm{Heusler}$ alloy, Scr. Mater. 145, 58 (2018).

[94] X. He, Y. Kang, S. Wei, Y. Zhang, Y. Cao, K. Xu, Z. Li, C. Jing, and Z. Li, A large barocaloric effect and its reversible behavior with an enhanced relative volume change for $\mathrm{Ni}_{42.3} \mathrm{Co}_{7.9} \mathrm{Mn}_{38.8} \mathrm{Sn}_{11} \mathrm{Heusler}$ alloy, J. Alloys Compd 741, 821 (2018).

[95] T. Samanta, P. Lloveras, A. U. Saleheen, D. Lepkowski, E. Kramer, I. Dubenko, P. Adams, D. Young, M. Barrio, J.-L. Tamarit, N. Ali, and S. Stadler, Barocaloric and magnetocaloric effects in $(\mathrm{MnNiSi})_{1-x}(\mathrm{FeCoGe})_{x}$, Appl. Phys. Lett. 112, 021907 (2018) 
[96] I. N. Flerov, M. V. Gorev, A. V. Kartashev, E. I. Pogoreltsev, and N. M. Laptash, Heat capacity, thermal expansion and barocaloric effect in fluoride $K_{2} T_{a} F_{7}$, J. Mater. Sci. 54, 1573 (2019).

[97] E. Stern-Taulats, P. Lloveras, M. Barrio, E. Defay, M. Egilmez, A. Planes, J.-L. Tamarit, L. Mañosa, N. D. Mathur, and X. Moya, Inverse barocaloric effects in ferroelectric $\mathrm{BaTiO}_{3}$ ceramics, APL Mater. 4, 091102 (2016).

[98] M. V. Gorev, E. A. Mikhaleva, I. N. Flerov, and E. V. Bogdanov, Conventional and inverse barocaloric effects in ferroelectric $\mathrm{NH}_{4} \mathrm{HSO}_{4}$, J. Alloys Compd. 806, 1047 (2019).

[99] P. von Ranke, B. Alho, and P. Ribeiro, First indirect experimental evidence and theoretical discussion of giant refrigeration capacity through the reversible pressure induced spin-crossover phase transition, J. Alloys Compd. 749, 556 (2018).

[100] P. J. von Ranke, B. P. Alho, R. M. Ribas, E. P. Nobrega, A. Caldas, V. S. R. de Sousa, M. V. Colaço, L. F. Marques, D. L. Rocco, and P. O. Ribeiro, Colossal refrigerant capacity in [Fe (hyptrz) $\left.{ }_{3}\right] \mathrm{A}_{2} \cdot \mathrm{H}_{2} \mathrm{O}$ around the freezing temperature of water, Phys. Rev. B 98, 224408 (2018).

[101] P. von Ranke, B. Alho, E. Nobrega, A. Caldas, V. de Sousa, M. Colaço, L. F. Marques, G. M. Rocha, D. L. Rocco, and P. Ribeiro, The refrigerant capacity in spin-crossover materials: Application to $\left[\mathrm{Fe}(\text { phen })_{2}(\mathrm{NCS})_{2}\right]$, J. Magn. Magn. Mater. 489, 165421 (2019).

[102] J.-J. Lee, H.-s. Sheu, C.-R. Lee, J.-M. Chen, J.-F. Lee, C.-C. Wang, C.-H. Huang, and Y. Wang, Xray Absorption Spectroscopic Studies on Light-Induced Excited Spin State Trapping of an Fe(II) Complex, J. Am. Chem. Soc. 122, 5742 (2000).

[103] S. Patel, A. Chauhan, R. Vaish, and P. Thomas, Elastocaloric and barocaloric effects in polyvinylidene di-fluoride-based polymers, Appl. Phys. Lett. 108, 072903 (2016).

[104] E. Usuda, N. Bom, and A. Carvalho, Large barocaloric effects at low pressures in natural rubber, Eur. Polym. J. 92, 287 (2017).

[105] A. Carvalho, W. Imamura, E. Usuda, and N. Bom, Giant room-temperature barocaloric effects in $\{P D M S\}$ rubber at low pressures, Eur. Polym. J. 99, 212 (2018).

[106] E. O. Usuda, W. Imamura, N. M. Bom, L. S. Paixão, and A. M. G. Carvalho, Giant Reversible Barocaloric Effects in Nitrile Butadiene Rubber around Room Temperature, ACS Appl. Polym. Mater. 1, 1991 (2019).

[107] W. Imamura, E. O. Usuda, L. S. Paixão, N. M. Bom, A. M. Gomes, and A. M. G. Carvalho, Supergiant Barocaloric Effects in Acetoxy Silicone Rubber over a Wide Temperature Range: Great Potential for Solid-state Cooling, Chin. J. Polym. Sci. 38, 999 (2020).

[108] E. Stern-Taulats, A. D’Ammaro, A. Avramenko, A. Robinson and X. Moya, First steps towards barocaloric refrigeration, Thermag VIII, 8th IIR, IIF International Conference on Caloric Cooling, International Institute of Refrigeration (2018).

[109] X. Moya and W. J. Averdieck, Barocal Ltd. https:// barocal.com (accessed October 2020)

[110] W. Gao, R. Brennan, Y. Hu, M. Wuttig, G. Yuan, E. Quandt, and S. Ren, Mater. Energy transduction ferroic materials, Mater. Today 21, 771 (2018). 